\title{
Histological Alteration Induced by Manganese chloride in the Male Testes, Epididymis and Kidney of the Albino Rats
}

\author{
${ }^{1}$ Nuha, ${ }^{2}$ Y. AL-Harbi \\ (Biology sciences/Babylon university/Iraq)
}

\begin{abstract}
In Iraq. the municipalities are responsible for the production and delivery of drinking water (DW) .The quality of DW in Iraq is greatly deteriorated because of the war operation in this country Objective to study the effects of manganese chloride on histological testes, epididymis and kidney of rats and explore the dose-effects and time effects. The rats are randomly divided into six treatment groups with manganese chloride $(60,80,100$ ppm) and 2 control groups with N.S. After two different periods (3 and $6 \mathrm{mn}$.) oral administration Mncl 2 by drinking water $(60,80,100 \mathrm{ppm})$ to investigate testicular and epididymis histological alterations of manganese chloride caused interstitial and tubular histological alterations that include atrophy of seminiferous tubules , autolysis and granulolysis of epididymis.

Histopathological, the most striking lesion were observed in the kidney .the high dose of Mn+2 (100 ppm) for two periods caused on opposite effect on nephrotoxicity. Causing exacerbation in the tubular necrosis. Keyword-Histological alteration, Liver, Manganese chloride, Rat, Reproductive system
\end{abstract}

\section{Introduction}

The pollution with metals is a serious concern ,because potential contamination of drinking water sources can change from soil contamination. Some heavy metals have bio-impotance as trace elements but , the biotoxic effects of many of them in human biochemistry are of great concern .Hence, there is the need for proper understanding of the conditions, such as the concentrations and idation, which make them harmful, and how biotoxicity occurs[ 1]

Manganese is an essential trace element in humans that can elicit a variety of serious toxic responses upon prolonged exposure to elevated concentration either orally or by inhalation. [ 2] Manganese is often regarded as one of the least toxic metals by the oral route because homeostasis limits the gastrointestinal absorption .However, there is increasing evidence of neurotoxicity by the oral route especially in infants[3] . Manganese in drinking water may be more bioavailable than manganese in food. However, The IOM report also noted the potential for greater absorption of manganese in water compared to food. [4].

Many reports indicate that oral exposure to manganese, especially from contaminated water sources, can produce significant health effects. Manganese accumulation in the kidneys in both fetal and female rats during pregnancy and a variety of histological effects in renal tissue and renal failure was associated with the ingestion of manganese containing fertilizer [ 5\&6] .

Trace elements are essential for the function of various enzymes and other proteins . The effects of trace element biochemistry and physiology on parameters of fertility are presented for zinc, selenium ,iodine, copper and manganese [ 7]. The sodium suproxide ( SOD) is a important enzyme among enzymes system that eliminates free radicals. The manganese is able to inhibit SOD by forming free radicals [ 8] .Therefore chronic parenteral administration of manganese produced marked degenerative changes in the seminiferous tubules [9] .

A number of experimental and epidemiological studies on the genotoxic effects of metals, these demonstrate the manganese is clastogens inducing chromosomal aberrations, micronuclei induction, sister chromatid exchange ( SCE) and chromosomal loss in human and anima 1 cells [ 10\&11].

\section{Materials And Methods}

The present investigation was carried out in the center of experimental of Biology in Babylon University . A total of 40 adult males of the albino rats of the same age and weighting 200-240 g were used in this study .Rats were randomly divided into eight groups [ number of animals in each group $(n)=5$ ] . Three groups , designated groups 1-3, were exposed to ascending concentrations of manganese chloride ( 60,80 and $100 \mathrm{ppm}$ ) in drinking water for 3 months. The fourth group was used as a control received normal saline. And another three groups were exposed to the same concentrations of $\mathrm{MnCl} 2$ in drinking water for 6 months and one group was used as a control.

All groups were fed on a standard laboratory animal diet pellet and maintained under standard laboratory conditions that included controlled temperature and light, dark periods (12: 12) .

The animals were sacrificed and representative tissue specimens from both tests, epididymis and kidney of each rats were removed rapidly and fixed in neutral buffered formalin ( $10 \%)$. Tissue specimens 
were then dehydrated in ascending grades of ethanol ( 70, 80, 90, 95 and $100 \%$ ) cleared in 2 changes of chloroform, impregnated with 2 changes of molten paraffin wax and finally embedded and blocked out. Tissue sections ( $4-5 \mu \mathrm{m})$ were stained with hematoxylin and eosin (HE) according to [12].

\section{Results}

Representative histological abnormalities in the cortical kidney area after 3 and 6 months of 60,80 ppm Mncl2 oral adminstration, mild-to- moderate tubular necrosis " fig ." 1 a\& b. However ,marked vacoulation of the cortical convoluted tubules was detected in rats to $100 \mathrm{ppm}$ for 3 months .Coagulative tubular necrosis was apparent in rats that received 100 ppm for 6 months" fig.1"c \& d

Manganese chloride induced marked changes in the testicular tissues and epididymis tissues of the exposed rats and included interstitial and tubular alterations.

Atrophy of semeniferous tubules Occasional tubular atrophy was observed after 3 months of exposure to $100 \mathrm{ppm}$ Mncl2 .However .marked atrophy of seminiferous tubules with complete arrest of spermatogenesis was detected in rats exposed to 100 ppm manganese chloride for 6 months " fig." 2 a \& b .

Autolysis and granuolysis Accumulation of coiled substances was observed in the lumens of epididymis in rats exposed to $100 \mathrm{ppm} \mathrm{Mncl} 2$ for 3 months . Granulolysis of epididymis was apparent in rats that received 100 ppm Mncl2 for 6 months. "fig ." 3 a \&b .

\section{Discussion}

Results showed that Mncl2 exposure resulted in liver injury in rats and the extent of injury correlated positively with exposure time .

Histopathologicaly, the most striking lesions were observed in the kidneys of male rats .In the current study the early change in convoluted tubular tissue was observed in animals of all treatment groups . [13] reported a changes in trace elements levels showed structural damage in different organs such as the liver ,kidney and spleen . The kidney tubular necrosis in the present study may be due to the oxidative damage induced by manganese chloride. Mn has an especial affinity with the mitochondrial and can largely accumulate in the cells contain plentiful mitochondrial ,So the manganese content is highest in the liver and the content is higher in the kidney and brain [14].

Zhang et al. found the manganese can accumulate in mitochondria and inhibit efflux of calcium. There is a significant inverse correlation between the amount of suproxide radicals and the specific activities of the mitochondria enzymes [15]. Again the results of the present study was in accordance with previous studies that Sprague -Dawley male rats treated with high manganese dose developed severe renal disease [16]. But in these study the Wister Albino rats treated with gentamicin and manganese chloride ( $20 \mathrm{mg} / \mathrm{kg}$ per day ) showed severe tubular necrosis [17]. Other investigator concluded that tissue accumulation of Mn was greater by IP treatment could be explained by the existence of competition between iron (Fe ) and $\mathrm{Mn}$ that may appear, notably, as adisturbance in the functioning of the respiratory chain in the cells (incomplete $\mathrm{O} 2$ reduction and formation of free radicals and oxygenated compound ). Leading to cellular degeneration [18].

The results of the present investigation showed that $100 \mathrm{ppm} \mathrm{MnCl} 2$ exposure for 3 and 6 months caused atrophy of seminiferous tubules and autolysis and granulolysis of epididymis. These findings are in agreement with that reported by[19]. Who reported oral manganese chloride exposure seems to trigger reduced fertility in mice at very high doses . Moreover, a damage of mice testis was serious with increase of dose and time exposed to manganese chloride ; After $56 \mathrm{~d}$ of $\mathrm{MnCl} 2$ exposure might damage seminiferous tubule and semimiferous epithelial cells[20 ].

The atrophy of seminiferous tubule and autolysis and granulolysis of epididymis in the present study may be due to the oxidative damage induced by manganese chloride .The oxidative damage might have destroyed most of the germ cells either due to the membrane damage or macromolecular degradation incurred by ROS leading to atrophy of seminiferous and autolysis of epididymis . Again the results of the present study was in accordance with previous study that oxidative stress being present in the testes after in vivo treatment of rats with manganese chloride [ 21]. Metals may operate through hormonal or genotoxic pathways to affect male reproduction .Metals may penetrate the blood testis barrier to potentially affect spermatogenesis, either by affecting genetic integrity or hormone production .Effects may be at different stages of the cell cycle such as during meoitic disjunction and such abnormalities can have deleterious effects on reproduction and offspring [ 22 ] . [23] Who reported that manganese has the mutagenicity on reproductive cells of male mice when injecting manganese chloride i.p. in mice at $50 \mathrm{mg} \mid \mathrm{kg}$. [ 24]these findings that manganese acts as an antagonist of iron, disrupting the enzymatic activity and inhibited protein and gene expression .Cheng etal . Found that manganese induced mitochondrial dysfunction and disturbance of calcium hemostasis contribute to the adverse effects on the leydig cells at the early |immediate stage after treatment ( 2 and $4 \mathrm{~h}$.). However at later stages ( 24 and $48 \mathrm{~h}$. ) manganese could arrest the cell cycle induce apoptosis of primary leydig cells [25] 
Manganese chloride at the dose of $15 \mathrm{mg} \mid \mathrm{kg}$ and $30 \mathrm{mg} \mid \mathrm{kg}$ could induce apoptosis of spermatogenic cells[ 26] . For rats Xiulian etal. Found $15 \mathrm{mg} \mathrm{kg} \mathrm{MnCl} 2$ exposure for $4 \mathrm{Wks}$ could promote the expression of caspase- 3 and inhibit the expression of $\mathrm{Ki}-67$ in rat spermatogenic cells .It may be an important mechanism of spermatogenic dysfunction[27].

\section{Conclusion}

The results of the present study indicate that $\mathrm{MnCl} 2$ exposure resulted in liver injury in rats correlated positively with exposure time .Moreover, our investigation has demonstrated that histological alterations of testis and epididymis depend on dose effect and time effect.

\section{References}

\section{Journal papers:}

[1] J.O. Duruibe, , M.O. Ogwuegbu, and J.N. Egwurugwu, Heavy metal pollution and human biotoxic effects , International Journal of Physical Sciences, 2 , 2007,112-118

[2] C. Judith, 1. Ruiz, G. Ciria, and S. Figueroa, Manganese inactivation of renal betaine aldehyde dehydrogenase from swine . EXCLI Journal, 5, 2006, 140- 149

[3] U.S. EPA, Health effects support document for manganese. U.S.Environmental Protection Agency ,Washington ,DC ,2003, EPA 822 - R- 03- 003.

[4] IOM , Dietary Reference Intakes for Vitamin A, Vitamin K, Arsenic , Boron , Chromium ,Copper , Iodine , Iron , Manganese ,Myolybdenum ,Nickel ,Silicon , Vanadium ,Zinc .Food and Nutrition Board . Institute of Medicine . National Academy Press ,Washington ,2001, $10-22$.

[5] Z . Bijia, Effect of manganese of genital system of male mice .Toxic, 1994, $04-015$.

[6] WH. Huang, and JL. Lin, Acute renal failure following ingestion of manganese - containing fertilizer . Toxicol .Clin . Toxicol, 42,2004, 305- 307 .

[7] S. Leonhard -marek, ( 2000 ) : Why do trace elements have an influence on fertility . Tierarztliche Praxis Ausgabe Grobtiere Nutztiere, 28,2000, $60-65$.

[8] B. Yan zhang ; C. CHEN, and F. Liye, Effect of manganese on heat stress protein synthesis of new born rats . World J Gastroenterol ,8, 2002, $114-118$.

[9] WHO Guidelines for dringing - water guality, Health criteria and other supporting information. World Health Organization , Geneva $1996,2^{\text {nd }}$ edition Vol 2.

[10] M. Joardar , and A. Sharma, A comparison of clasto genecity of inorganic Mn administered in cationic and anionic forms in vivo . Mutat Res, 240,1990.

[11] G. Li , J. Ghu, Q. Wu, and Y. Gu, Effect of manganese on the ratio of micronucleus cells in mice marrow . WeiShengYanJiu , 137(30),2001.

[12] A.E. Pearse, Histochemistry : Theoretical and Applied . Churchill Livingstone ,Edinburgh .1985, $4^{\text {th }}$ End Vol 2.

[13] H. Abul, T.C. Mathew, F. Abul, andH. Al-Sayer, Trace element levels in the testes of hioacetamide-induced cirrhotic rats .The Journalof Trace Elements in Expermental Medicine . 14(4),2001, 383-392 .

[14] S. Erdogan, S Celik, and Z. Erdogan, Seasonal and locational effects on serum, milk, liver and kidney chromium ,manganese ,copper ,zinc and iron concentrations of dairy cows .Biol. Trace Elem. Res. , 98 ,2004, 51-61.

[15] S. Zhang, Z. Zhou, and Fu.Juan ling, Effect of manganese chloride exposure on liver and brain mitochondria function in rats . Evironmental Research, 93 ( 2),2003, 149-157.

[16] T. Ponnakkam, M. Iszard, and G. Henry, Effect of oral administration of manganese on the kidneys and urinary bladder of Sprague-Dawley rats.Int J Toxicol ,22(3), 2003, 227-32.

[17] A. Atessahin, I. Karahan, S. Yilmaz, and A. Cerbasi, The effect of manganese chloride on gentamicin - induced nephrotoxicity in rats. Pharmacol Res , 48, 2003, 637-642.

[18] P. Missy, M. Lanhers, L. Cunat , and M. Joyeux , Effect of sub chronic exposure to manganese chloride on tissue distribution of three essential elements in rats . International Journal of Toxicology, 19,2000, 313-321.

[19] A. Elbetieha, H. Bataineh, and H. Darmani, (2001) : Effects of long term exposure to manganese on fertility of male and female mice . Toxicoloy letters, 119,,2001, 193-201.

[20] Cai . Xiulian, LI. Xingsheng, and LI . Jirong, Effects of manganese chloride on the morphology of testis . Acta Academiae Medicinae Zunyi ,2006, 03-000.

[21] Y. Wu, J. Cui , and J. Wang, Study on mechanisms of subacute reproductive toxicity in male rats exposed to manganese chloride . Chinese Journal of Industrial Medicine, 2004,03-000.

[22] N. Mathur, G. Pandey, and G. Jain, Male reproductive toxicity of some selected metals :Areview . Journal of Biology Sciences , 5, 2010, $396-404$.

[23] Zi. Wang, Y. Li, and L. Lin, Study on the mutagenicity of manganese chloride in reproductive cells of male mice . Chinese Journal of Industrial Medicine, 2002,01-004 .

[24] T. Hung, C. Lang, and J. Heng , Manganese antagonizes iron blocking mitochondrial a conitase expression in human prostate carcinoma cells . Asian Journal of Andrology,8(3), 2006, 307-315.

[25] J. Cheng, Fu. Juanling, and Z. Zhou, The mechanism of manganese induced inhibition of steroidogenesis in rat primary leydig cells. Toxicology,211(2), 2005, 1- 11 .

[26] Cai. Xiulian, , Z. Xianping, ,W. Guoxiu and G. Hai, Effects of glutathione on apoptosis and proliferation of spermatogenic cells of rats exposed to manganese .Chinese Journal of Anatomy, 2008, 03-014.

[27] Cai. Xiulian, G. Hai , and W. Guoxiu , Effects and significance of manganese on expression of capase- 3 and ki - 67 in spermatogenic cells of rats . Cinese Journal of Public Health ,2009, 08-050. 

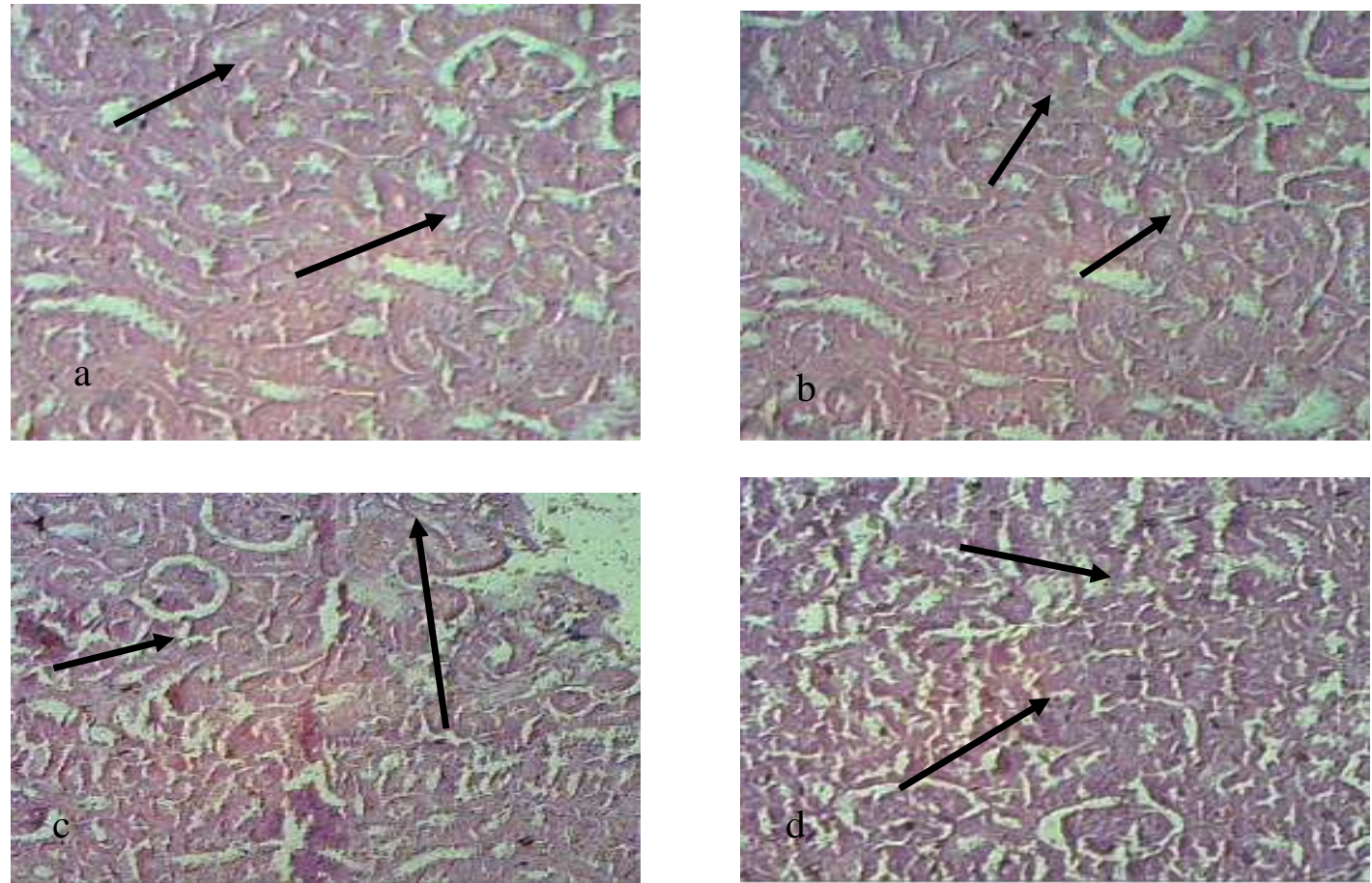

"Fig "1: Light micrograph sections stained with hematoxylin and eosin, showing : a\&b: The many cortical convoluted tubules are revised by necrotic cells (arrows), $80 \mathrm{ppm} \mathrm{MnCl2} \mathrm{for} 3$ and 6 months. c: Vacoulation of the cortical convoluted tubules (arrows), 100 ppm for 3 months. $d$ : Coagulative tubular necrosis (arrows), 100 pmm manganese chloride for 6 months.
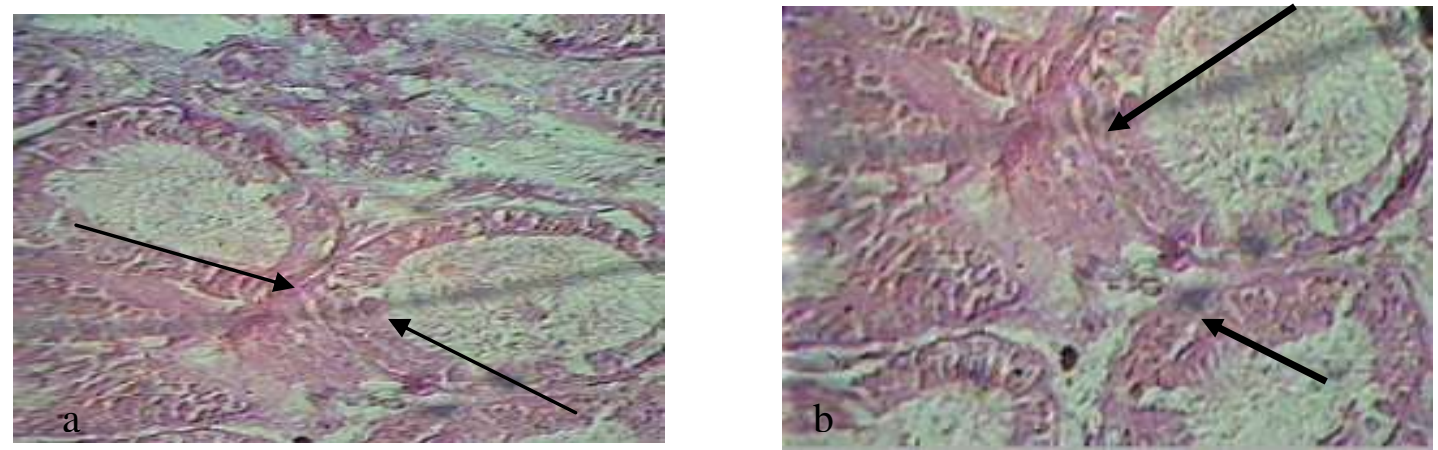

"Fig." 2 : Light micrograph sections stained with hematoxylin and eosin, showing :

a: Testicular atrophy was observed after 3 months of exposure to 100 ppm of manganese chloride . b: Sever necrosis, vacoulated seminiferous tubules necrosis , 100 ppm MnCl2 for 6 months.
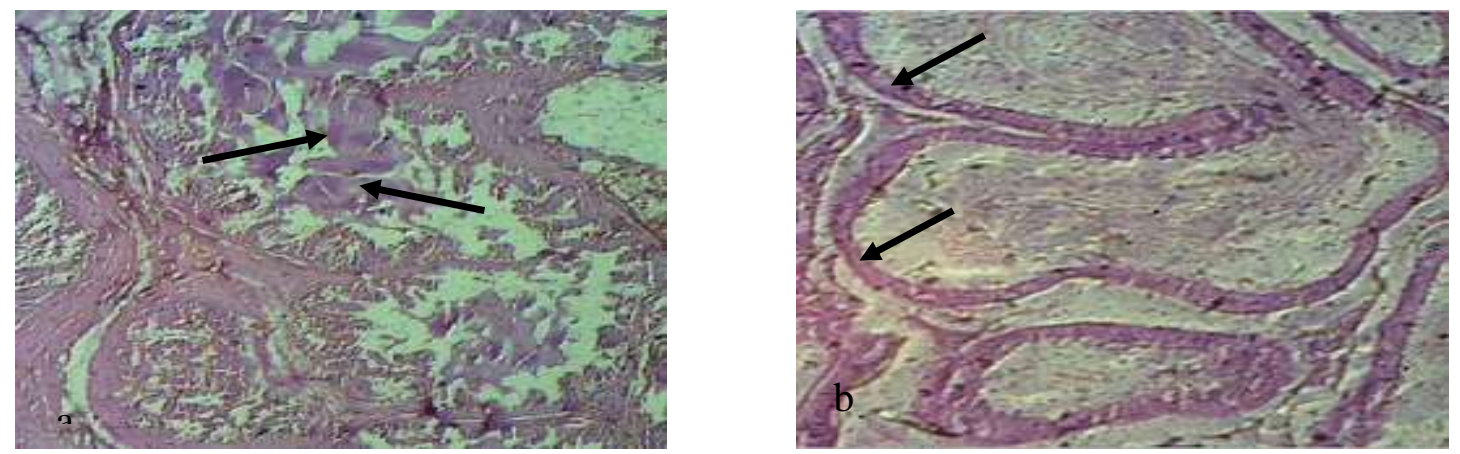

"Fig."3: Light micrograph sections stained with hematoxylin and eosin, showing :

a: Accumulation of coiled substances in lumen of epididymis, autolysis 100 ppm for 3 (arrows).

b: Granulolysis of the endothelial cells, 100 ppm for 6 months (arrows ). 